\title{
Well Control using Drill Sim (One Circulation)
}

\section{Ilavalagan}

\begin{abstract}
The Usage Of Petroleum In Daily Life Have Increased Much Where The Petroleum Industry Also To Be Develop To Match With The Need. Drilling, An Task Where Petroleum Is Pointed And The Location Is Drilled To Take Out The Petroleum And Petroleum Sub Products From Subsurface To The Surface. Drilling A Well Is Not Also An Easy Way It Have To Meet Some Problems Due To Formation Pressure, Hydrostatic Pressure Etc., To Maintain The Well And To Get Out The Petroleum Well Control Technique Were Used In The Industry. Well Control Means To Prevent The Kick And Safe Guard The Instruments And Peoples Working On The Well. There Were Two Methods To Control The Well, They Were One Circulation Method And Two Circulation Method. In This Paper I Used The Ari Drilling Simulator With Assumed Values And Run One Circulation Method And Finally Observing The One Circulation Method Results , Given My Conclusion.
\end{abstract}

Keywords: Drilling simulator, engineer method, drillers method, one circulation method etc.,

\section{INTRODUCTION}

Well control is an important operations in oil and gas field where it comes under drilling, well work over and well completions. with the help of AMET university, Chennai drilling simulator lab the work have been done

\section{METHODOLODY}

\section{A. One-circulation method :}

fig1 delineate the one circulation method. On point 1 the SIDP were used to enumerate the kill weight mud. To kill density the mud weight should be increased in the suction pit. When the kill mud pumped down through the drill pipe static drill pipe pressure have to control till decrease linearly until at point 2.Now the drill pipe pressure enhances to zero. The heavy mud killed the drill pipe pressure. Point 3 conveys the initial pumping pressure on the drill pipe Though the kill mud is pumping down through the pipe, circulating pressure decreases the bit until it reach the flow line, chokes were used to control the drill pipe pressure at the final circulation

Manuscript published on November 30, 2019.

*Correspondence Author

Ilavalagan*, Assistant Professor Department of Mining Engineering AME Tuniversity Chennai-603112. Tamil Nadu, INDIA

(C) The Authors. Published by Blue Eyes Intelligence Engineering and Sciences Publication (BEIESP). This is an open access article under the CCBY-NC-ND license http://creativecommons.org/licenses/by-nc-nd/4.0/

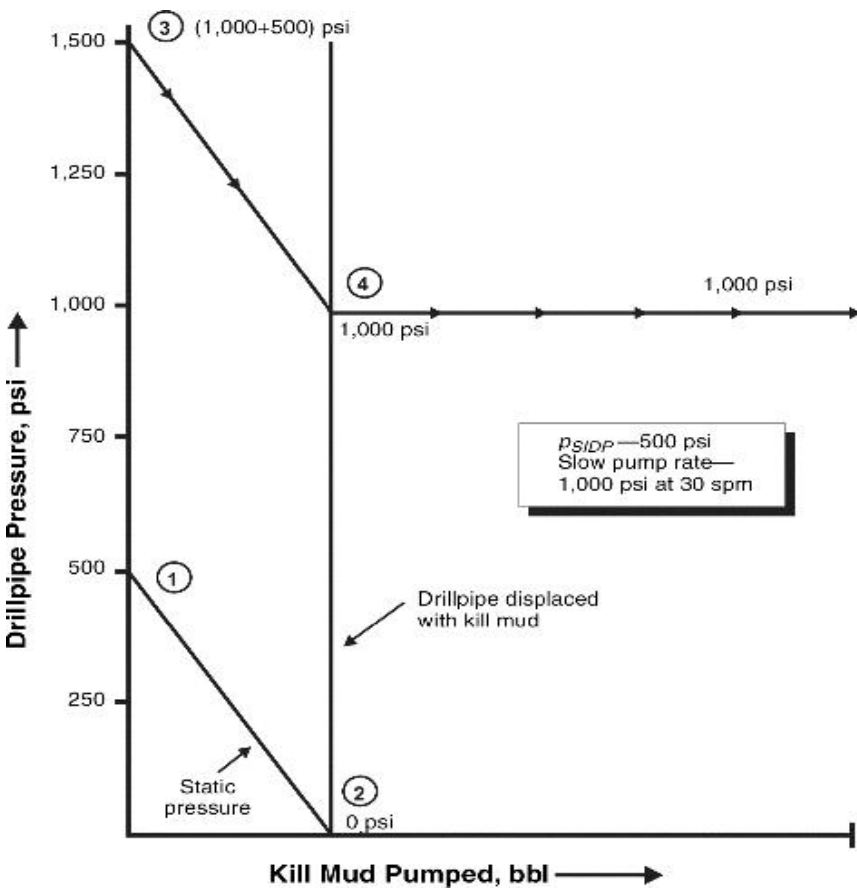

Fig. 1-Static drill pipe pressure of the onecirculation method of well control.

B. TIME:

Two important things were to be considered based on time they were initial wait time and the overall time required. First to be consider is the total amount required to increase the mud density from its original weight to final kill weight mud. Because some operators are very concerned with pipe getting stuck during this time, the well-control procedure that minimizes the initial wait time is often chosen.

\section{Well Control Simulator}

The ARI Well Control simulator is one of the most versatile and flexible training tools of its kind in the world.

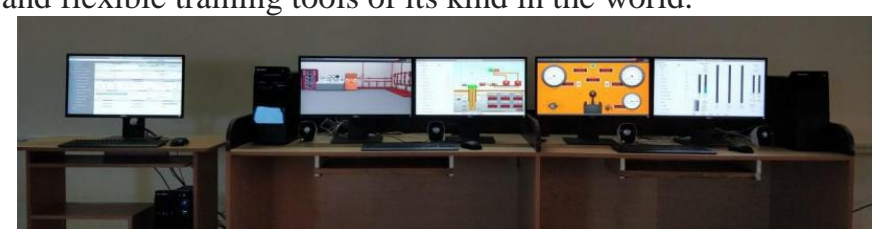

Fig. 2 - Well Control Simulator in Simulator lab, AMET, CHENNAI

Well Data

Drill Pipe:

$113 \times 44=4972 \mathrm{ft}$

O.D $=5$ inch.

P.P.F $=19.5 \mathrm{lb} / \mathrm{ft}$

I.D $=4.28$ inch.

Drill Collar:

$15 \times 44=660 \mathrm{ft}$.

O.D $=6.25$ inch.

P.P.F $=87.71 \mathrm{lb} / \mathrm{ft}$.

I.D $=2.50$ inch 
Well Data

Well Diameter $=8.5$ inch.

Well Depth $=5575.07 \mathrm{ft}$.

Mud Density = 10.26 ppg.

Casing Data

Casing O.D $=9^{5 / 8}$ inch.

I.D $=8.5$ inch.

P.P.F $=47 \mathrm{lb} / \mathrm{ft}$.

Surface casing $=3902.55 \mathrm{ft}$.

Casing shoe fracture pressure $=3653.26$ psi.

Dynamic Pressure loss $=221$ psi.

Kill Mud Weight $=12$ ppg.

ICP $=724$ psi.

$\mathrm{FCP}=251$ psi.

Pit Gain $=7$ bbl.

SICP $=403$ psi.

SIDPP $=494$ psi.

Well Control Methods

One circulation Method: 2hrs 05mins 50secs.

This Data have been used in the well control methods by the we control simulator (in simulator lab, AMET) for getting exact res

One circulation method:

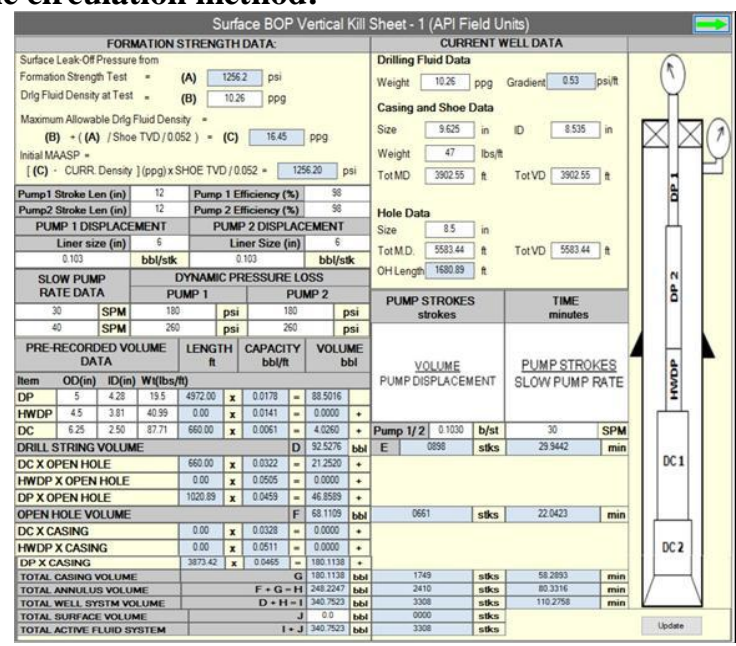

Fig: 3Kill Sheet 1 of one circulation method

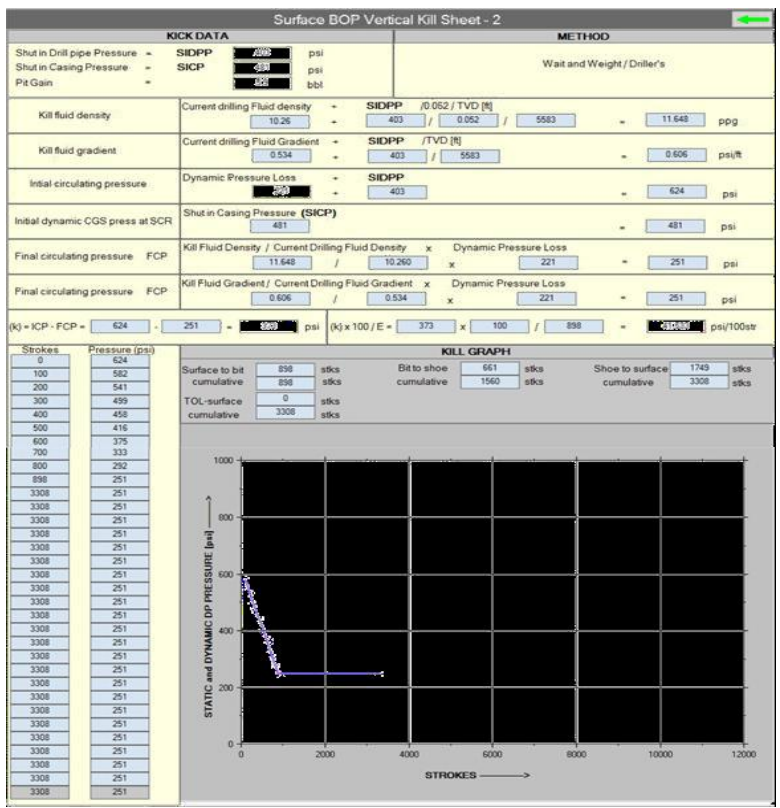

Fig:4 Killsheet2 One Circulation Method

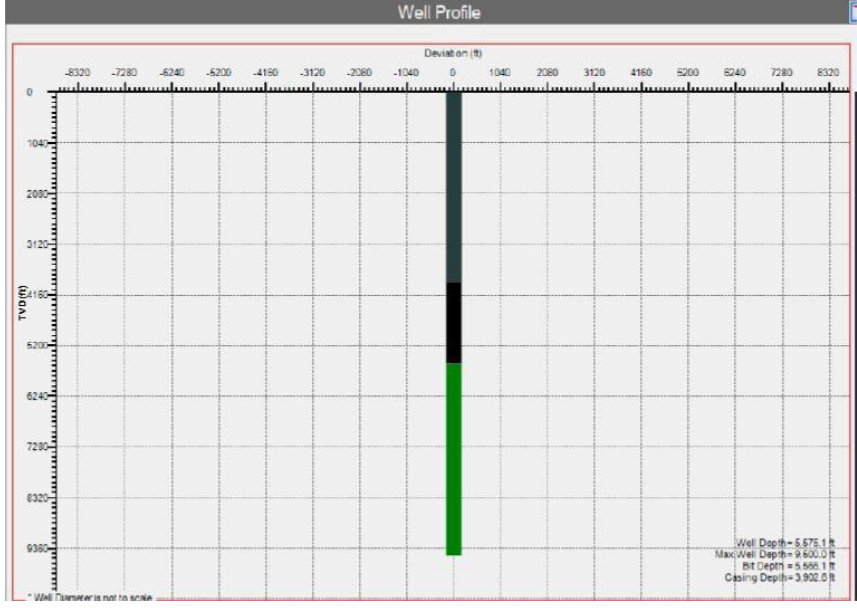

Fig: 5 Well Profile

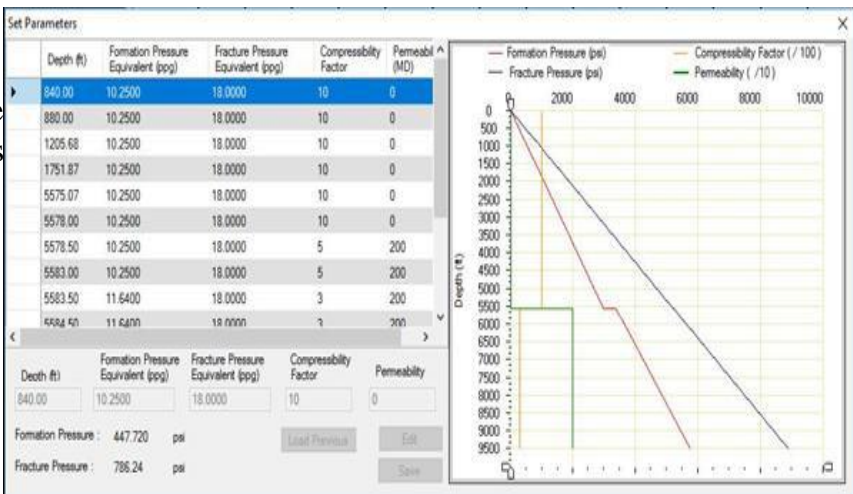

Fig:6 Formation Pressure and Fracture Pressure \& Drilling window of the formation

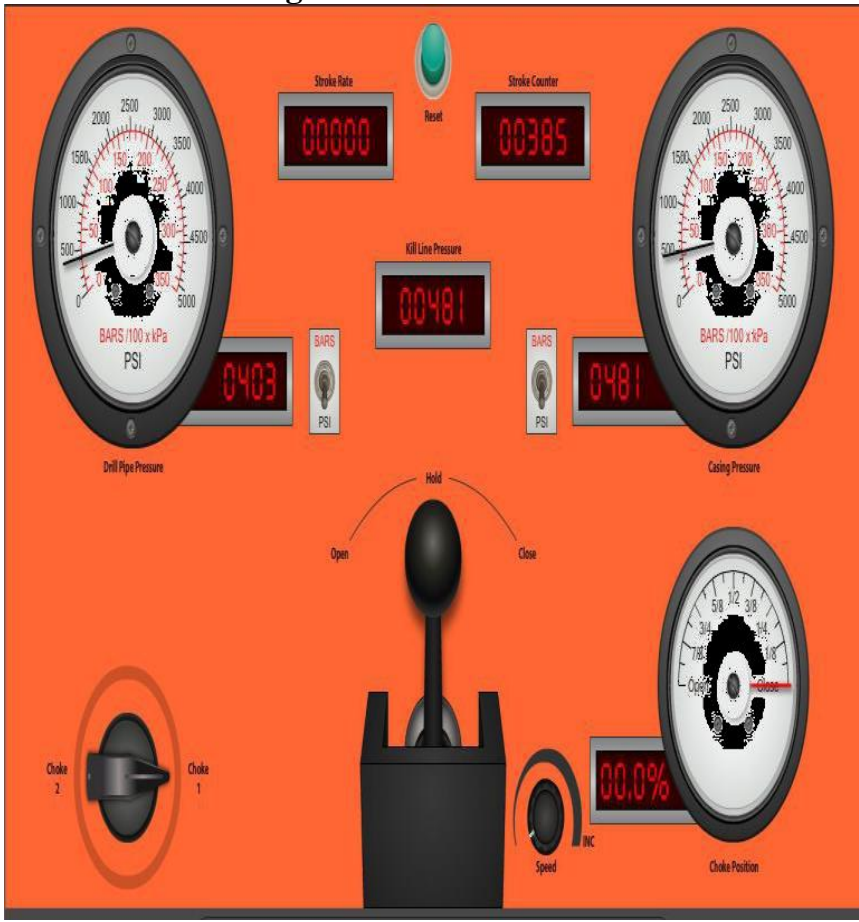

Fig:7 SIDPP and SICP of the well for Wait and Weight method 


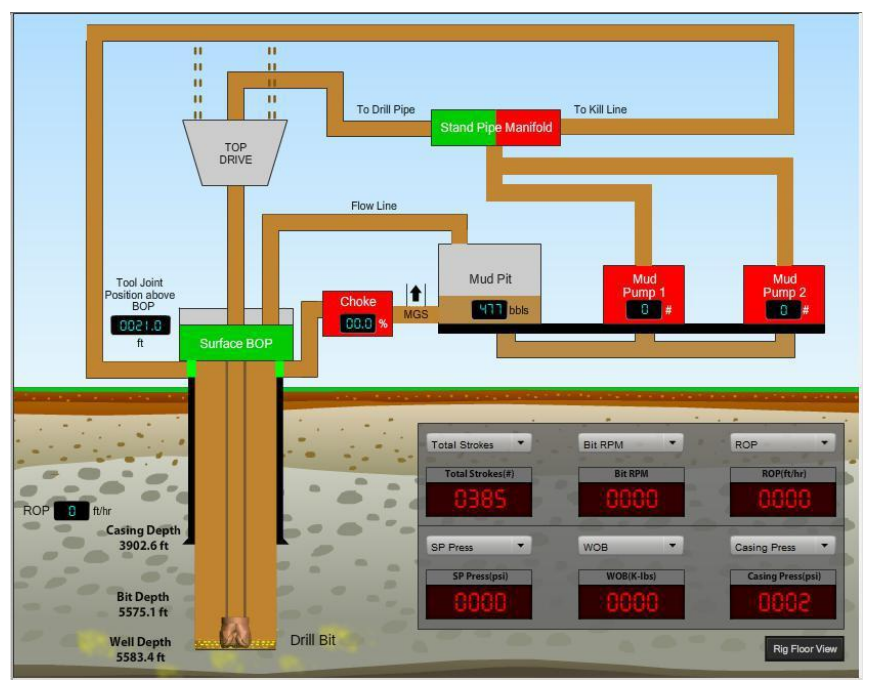

Fig:8 Kick encountered while drilling

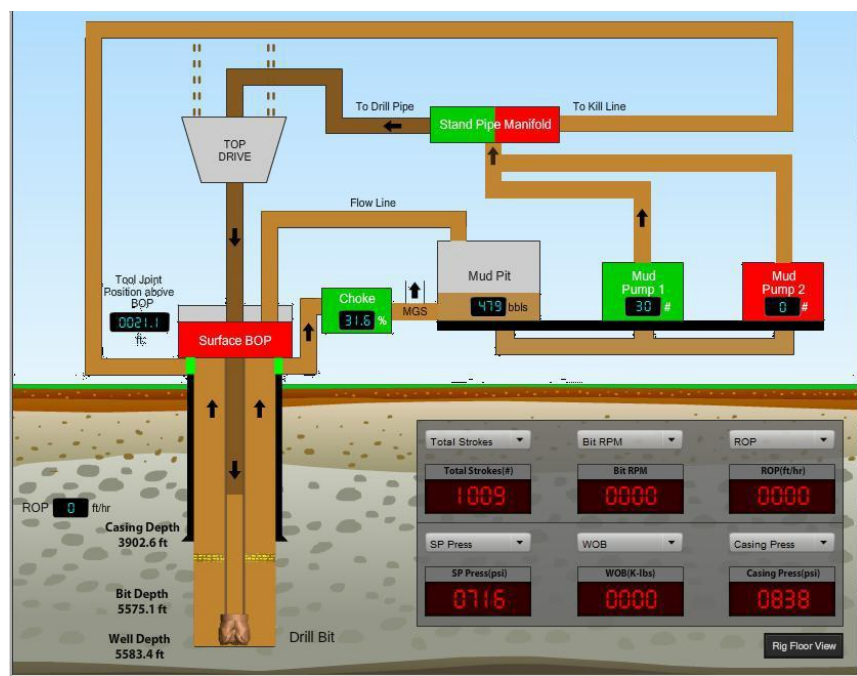

Fig:9 kick is circulated by using kill mud

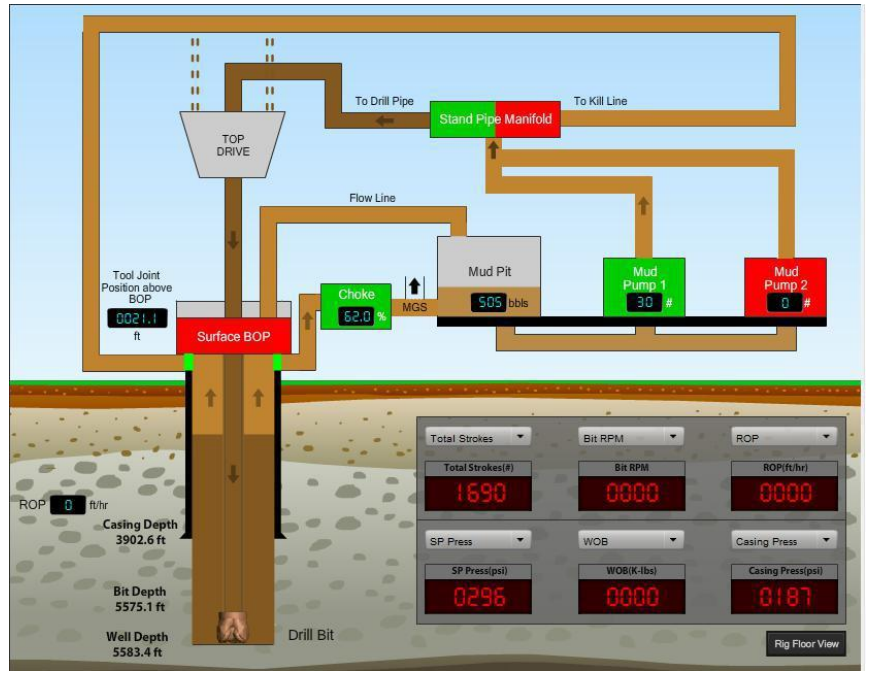

Fig:10 Kick is completely circulated out by the kill mud

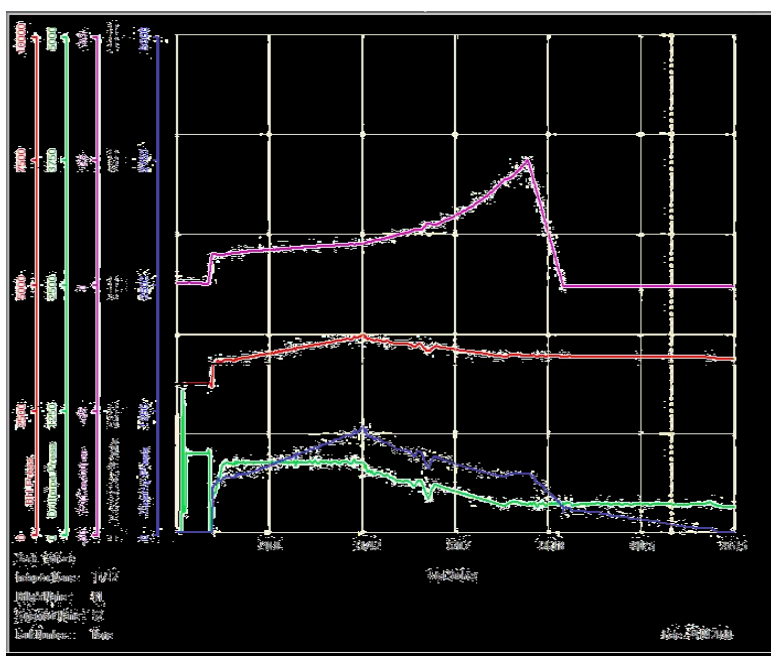

Fig: 11 Graph representing wait and weight method

\section{CONCLUSION}

- At initial stage both the formation pressure and the Bore Hole Pressure are at constant Level.

- When kick occurs at $5578.50 \mathrm{ft}$ i have raised the Bottom Hole Pressure by using choke and SIDP at this time intense we have used wait \& weight method both the formation pressure \& bore hole pressure were kept almost constant.

- During one circulation method at initial the casing pressure rises then drill pipe pressure, when kick arrived around certain point both the casing pressure and drill pipe pressure met then the casing pressure goes to zero.

- If the casing pressure doesn't comes to zero then their is still kick available in the bore hole.

- Hence here the casing pressure becomes zero by using wait $\&$ weight method

\section{REFERENCE}

1. Well engineering and construction by Hussain Rabia pg-50,51,59,144,148,149,508,550,560,592

2. Drilling operations manual by IDT,Deharadun pg-289 to 301

3. http://ijasrm.com/wp-

content/uploads/2018/07/IJASRM_V3S7 689_280_282.pdf

4. http://www.jetir.org/papers/JETIR180Z009.pdf

\section{AUTHOR PROFILE:}

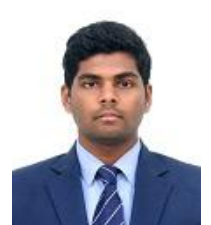

ILAVALAGAN $\mathbf{P}$, have graduated two maste degree one in Applied Geology and another one in Petroleum Engineering. Now working as an Assistant Professor in Mining Engineering Department of AMET university Chennai of Tami Nadu state. His Area of Research is mainly on subsurface exploration and determining the economic mineral and petroleum in subsurface have published many articles related to petroleum and mining and also presented research papers in National and International Conferences Mobile number: 9123592750 Email id: ilavalagan07@gmail.com Address: Assistant Professor Department of Mining Engineering AME Tuniversity Chennai-603112. Tamil Nadu, INDIA

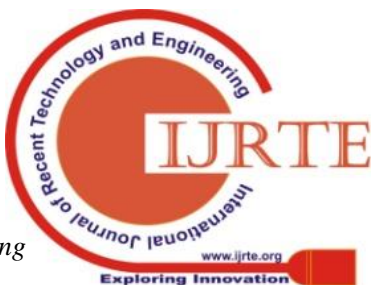

